\title{
Débridement and Reconstruction Improve Postoperative Sagittal Alignment in Kyphotic Cervical Spinal Tuberculosis
}

\author{
Zhimin Pan MD, Jiaquan Luo MD, PhD, Limin Yu MD, PhD, \\ Yiwei Chen MD, Junlong Zhong MD, Zhiyun Li MD, PhD, \\ Zhaoxun Zeng MD, Pingguo Duan MD, PhD, Yoon Ha MD, PhD, \\ Kai Cao MD, PhD
}

Received: 20 October 2016/Accepted: 24 February 2017/Published online: 6 March 2017

(C) The Association of Bone and Joint Surgeons \& 2017

\begin{abstract}
Background Cervical spinal tuberculosis is relatively common in some developing countries. It erodes vertebrae and discs, which sometimes results in cervical kyphosis and myelopathy. However, to our knowledge, no studies have evaluated improvements to patient-reported outcomes among patients who undergo surgical cervical sagittal realignment after kyphotic cervical spinal tuberculosis has been treated by débridement and reconstruction.

Questions/Purposes (1) Can a spine with kyphotic cervical spinal tuberculosis be returned to normal alignment and fused successfully? (2) Will patient-reported outcomes be improved with this intervention? (3) Are patient-reported outcomes correlated with realignment?

Methods Forty-six patients with kyphotic cervical spinal tuberculosis were evaluated in this retrospective study. We
\end{abstract}

The institution of one of the authors $(\mathrm{KC})$ has received, during the study period, funding from National Natural Science Foundation of China (No. 81460405, 81260399), Key Program of Jaingxi Provincial Department of Science and Technology (No. 20152ACB21024), Young Scientist Program of Jiangxi Province (No. 20133BCB23027), Program of Jaingxi Provincial Department of Science and Technology (No.20132BBG70068), and Research Program of Health and Family Planning Commission of Jiangxi Province (No. 20155087,

20155110).

All ICMJE Conflict of Interest Forms for authors and Clinical Orthopaedics and Related Research ${ }^{\circledR}$ editors and board members are on file with the publication and can be viewed on request.

Each author certifies that his or her institution approved or waived approval for the human protocol for this investigation and that all investigations were conducted in conformity with ethical principles of research.

This work was performed at the Department of Orthopaedics, the First Affiliated Hospital of Nanchang University, Nanchang, China; the Department of Spine Surgery, Peking University Shenzhen Hospital, generally performed surgery on patients with this condition when patients with cervical spinal tuberculosis presented with cervical kyphosis with or without neurologic deficits. Patients who did not meet these criteria were treated with other surgical procedures during the study period. Study patients were evaluated with cervical imaging, patient-reported outcomes questionnaires (Neck Disability Index [NDI], and the Japanese Orthopaedic Association [JOA] score), and physical examinations. Scores were collected by fellows preoperatively and at followup. No patient died during the followup. The mean followup was 26.8 months (range, 20-35 months). Preoperative and 2-year followup radiologic parameters were measured, including $\mathrm{C} 0-2$ Cobb angle, $\mathrm{C} 2-7 \mathrm{Cobb}$ angle, $\mathrm{C} 2-7$ sagittal vertical axis, center of gravity $(\mathrm{CG})$ to $\mathrm{C} 7$ sagittal vertical axis $(\mathrm{CG}-\mathrm{C} 7$ sagittal vertical axis), thoracic inlet angle, T1 slope, and

Shenzhen, China; and the Spine and Spinal Cord Institute of Yonsei University, Seoul, South Korea.

Z. Pan, J. Luo, Y. Chen, J. Zhong, Z. Li, Z. Zeng, P. Duan,

K. Cao $(\square)$

Department of Orthopaedics, The First Affiliated Hospital of

Nanchang University, 17 Yongwaizheng St., Nanchang 330006,

Jiangxi, China

e-mail: kaichaw@126.com

\section{Z. Pan, Y. Ha}

Department of Neurosurgery, Spine and Spinal Cord Institute,

Yonsei University College of Medicine, Seodaemun-gu, Seoul, Korea

L. Yu

Department of Spine Surgery, Peking University Shenzhen

Hospital, Shenzhen, Guangdong, China 
neck tilt. The correlations between cervical alignment and the NDI and JOA score were analyzed. Factors correlated with the NDI and JOA score improvements were identified by multiple stepwise regression analysis. CT was used to assess bone fusion after surgery.

Results All 46 patients showed bone fusion on CT scans. The preoperative $\mathrm{C} 0-2 \mathrm{Cobb}$ angle improved after surgery (mean difference, $5.0^{\circ} ; 95 \% \mathrm{CI}, 2.3^{\circ}-7.7^{\circ} ; \mathrm{p}=0.0068$ ), as did $\mathrm{C} 2-7 \mathrm{Cobb}$ angle (mean difference, $-33^{\circ} ; 95 \% \mathrm{CI}$, $-35^{\circ}$ to $\left.-31^{\circ} ; \mathrm{p}=0.0074\right), \mathrm{C} 2-7$ sagittal vertical axis (mean difference, $-28 \mathrm{~mm}$; $95 \% \mathrm{CI},-30 \mathrm{~mm}$ to $-26 \mathrm{~mm} ; \mathrm{p}=0.0036$ ), $\mathrm{CG}-7$ sagittal vertical axis (mean difference, $-26 \mathrm{~mm}$; $95 \% \mathrm{CI},-28 \mathrm{~mm}$ to $-24 \mathrm{~mm}$; $\mathrm{p}=0.0049$ ), $\mathrm{T} 1$ slope (mean difference, $6.0^{\circ} ; 95 \% \mathrm{CI}$, $3.7^{\circ}-8.3^{\circ} ; \mathrm{p}=0.0053$ ) and the thoracic inlet angle (mean difference, $8.0^{\circ} ; 95 \% \mathrm{CI}, 3.7^{\circ}-12^{\circ} ; \mathrm{p}=0.0072$ ). With the numbers available, the neck tilt angle did not improve (mean difference, $-0.2^{\circ} ; 95 \% \mathrm{CI},-1.0^{\circ}$ to $0.6^{\circ}$; $\mathrm{p}=0.079)$. The preoperative NDI of $34 \pm 5.1$ decreased to $17 \pm 4.6(\mathrm{p}=0.0096)$ at followup. Improvements in NDI were correlated with the magnitude of correction of the cervical deformities, including $\mathrm{C} 0-2 \mathrm{Cobb}$ angle $(\mathrm{r}=-0.357, \mathrm{p}=0.007), \mathrm{C} 2-7$ Cobb angle $(\mathrm{r}=0.410$, $\mathrm{p}=0.002)$, T1 slope $(\mathrm{r}=-0.366, \mathrm{p}=0.006$, thoracic inlet angle $(\mathrm{r}=-0.376, \mathrm{p}=0.005), \mathrm{C} 2-7$ sagittal vertical axis $(r=0.450, p=0.001)$, and CG-C7 sagittal vertical axis $(\mathrm{r}=0.361, \mathrm{p}=0.007)$. The JOA score improved to $13 \pm 2.6$ from $7.2 \pm 1.9$, which did not correlate with postoperative cervical realignment. After controlling for potential confounding variables like Cobb angles and T1 slope, we found $\mathrm{C} 2-7$ sagittal vertical axis was the most influential factor correlated with NDI improvement $(\mathrm{r}=0.450, \mathrm{p}=0.002)$.

Conclusion When treating kyphotic cervical spinal tuberculosis by débridement, decompression, and reconstruction, more attention should be drawn to realigning the cervical spine, in particular to restoring the $\mathrm{C} 2-7$ sagittal vertical axis. However, how best to restore the $\mathrm{C} 2-7$ sagittal vertical axis and cervical alignment in a kyphotic cervical spine needs further study.

Level of Evidence Level III, therapeutic study.

\section{Introduction}

Tuberculosis is a severe infectious disease that is relatively common in developing areas $[5,18,20,23,25]$. Cervical spinal tuberculosis occurs in $4.2 \%$ to $12 \%$ of patients with spinal tuberculosis [23], accounting for approximately $50 \%$ of patients with skeletal tuberculosis [4]. Antituberculosis chemotherapy can cure many patients with early cervical spinal tuberculosis, but surgery often is indicated in patients with cervical deformity, neurologic deficits, obvious necrotic tissue, or abscess owing to increased drug resistance [5].

Anterior bone grafting and instrumentation have been reported to be effective for managing cervical spinal tuberculosis $[15,24]$. This approach, after thorough anterior débridement, has been our general approach. However, to our knowledge, no studies have sought to correlate cervical sagittal realignment for patients with kyphotic cervical deformities from tuberculosis with improvements to patient-reported outcomes, which questionnaires generally are multidimensional, and assess a combination of aspects of impairments and/or disability. They reflect a patient's health status, and are means of gathering patients' views on recovery [3, 12]. Lee et al. [10] reported that patient-reported outcomes are associated with cervical sagittal alignment, however, not specifically in this population of patients.

The aim of our study therefore was to address the following questions: (1) Can a spine with kyphotic cervical spine tuberculosis be returned to normal alignment and fused successfully? (2) Will patient-reported outcomes be improved with this intervention? (3) Are patient-reported outcomes correlated with realignment?

\section{Patients and Methods}

Between June 2008 and October 2015 we performed 63 débridement and realignment procedures for patients with tuberculotic cervical spinal kyphosis at the First Affiliated Hospital of Nanchang University and Peking University Shenzhen Hospital. Of those, 17 (27\%) were lost to followup or had incomplete data, leaving 46 (73\%) for analysis in this retrospective study. These patients were evaluated with cervical imaging, patient-reported outcomes questionnaires (Neck Disability Index [NDI], and Japanese Orthopaedic Association [JOA] score), and physical examination. The NDI is a neck-pain-specific patient-reported outcomes tool [22], and it reflects how neck pain affects a patient's ability to manage in everyday life. The JOA score is a generalized index for assessment of objective cervical spinal cord functional status such as ambulation, sensation, and muscular tension [22].

No patient died during the followup. The mean followup was 26.8 months (range, 20-35 months). The study was approved by the institutional review boards of the two hospitals where the work was done. Informed consent for study participation was obtained from every patient. Diagnosis in all patients was made by preoperative clinical manifestations (neck pain, neck stiffness, fatigue, low fever, night sweats, and emaciation), radiologic findings 
(destruction of the vertebral body and intervertebral disc, cervical kyphosis, paravertebral abscess, and sequestra), laboratory test results (increased erythrocyte sedimentation rate $[\mathrm{ESR}]$ and $\mathrm{C}$ reactive protein concentrations [CRP]), and confirmed by postoperative pathologic examinations.

We generally performed surgery on patients with cervical spinal tuberculosis if they presented with cervical deformity (kyphotic Cobb angle $>0^{\circ}$ ), with or without neurologic deficits. However, patients who did not meet these criteria may have been treated with other surgical procedures during the study period. The criteria we used to guide the decision regarding the number of vertebral bodies to be removed included the number of vertebral bodies that were destroyed, the extent of the patient's apparent osteopenia, and the presence of visible sequestrate in the vertebral bodies. Exclusion criteria for the study were age younger than 18 years, cervical spinal tuberculosis without cervical kyphosis (kyphotic Cobb angle $\leq 0^{\circ}$ ), inflammatory disorder, tumor, spinal cord diseases such as intramedullary tumors but compression of the cord, administration of steroids, or severe comorbidities.

Thirty-nine patients had lesions in two vertebrae and seven had lesions in three vertebrae. The mean duration of disease was $3.5 \pm 1.6$ months (Table 1). All patients achieved bony fusion in a mean of 8 months (range, 612 months). Patients with one or two eroded segments underwent surgery through an anterior approach alone regardless of whether autograft or allograft was used. Patients with three or more eroded segments underwent surgery through an anterior approach if the tricortical iliac crest, as autograft, was used to reconstruct the cervical lordosis. However, if allograft was used in three or more involved segments, a combined anterior and posterior approach was performed.

Table 1. Patient demographic and clinical characteristics

\begin{tabular}{ll}
\hline Characteristics & Number (46 patients) \\
\hline Age (years) & $42 \pm 9$ \\
Gender & \\
Male & 27 \\
Female & 19 \\
Course of disease (months) & $3.5 \pm 1.6$ \\
Cervical tuberculosis location & \\
C3-4 & 6 \\
C4-5 & 17 \\
C5-6 & 15 \\
C6-7 & 1 \\
C3-5 & 4 \\
C4-6 & 3 \\
\hline
\end{tabular}

Surgical Technique

The patients were placed in a supine position with neck extension after receiving general anesthesia. A right anterior transverse incision was made. Layered exposure was performed along the medial border of the sternocleidomastoid muscle. The abscess was exposed, pus was suctioned, and the necrotic vertebral bone and disc were resected until healthy bone was reached. A sample was obtained and sent for pathologic examination. Tricortical iliac bone or titanium mesh with granular bone was implanted intervertebrally to maintain cervical lordosis after complete decompression of the spinal cord. Fluoroscopy was used to confirm the location of implants before drainage.

\section{Postoperative Care and Followup}

Cefazolin and antituberculin drugs were administrated for 48 hours and 12 months after surgery, respectively. Twelve patients received physical therapy in private clinics by their own choice. Patients wore a hard cervical collar for 3 months after surgery. Mean followup was not less than 24 months. NDI and JOA scores were assessed and recorded before surgery, after surgery, and at the mostrecent followup by clinical fellows. CRP and ESR were used to monitor activity of the tuberculosis. Radiographs and CT scans were taken to assess bone fusion. The CT criteria used for diagnosing fusion is based on bridging bone through the mesh or graft, which was assessed by two of us (ZP and LY)

\section{Radiologic Measurements}

All parameters were measured on the radiograph of the cervical spine taken with the patient in the upright position before surgery and at followup. Parameters of cervical alignment [7, 11, 19] including $\mathrm{C} 0-2$ Cobb angle, $\mathrm{C} 2-7$ Cobb angle, C2-7 sagittal vertical axis, center of gravity (CG) to C7 sagittal vertical axis, thoracic inlet angle, T1 slope, and neck tilt were measured (Fig. 1).

\section{Statistical Analysis}

All statistical analyses were performed using SPSS Version 19.0 statistical software (IBM Japan, Tokyo, Japan). Data are presented as mean and SD. A probability less than 0.05 was considered statistically significant. Preoperative and followup NDI and JOA score were compared by paired $t$ test. Correlations between cervical alignment and patient- 
Fig. 1A-E (A) The preoperative tuberculotic kyphotic cervical spine and alignment parameters and (B) followup lordotic cervical spine and realignment parameters are shown. (C) The preoperative MR image shows the tuberculotic lesion associated with eroded bone and the intervertebral disc, collapsed vertebrae, paravertebral abscess, compressed cord, and regional kyphosis. (D) An MR image obtained immediately postoperative shows the entire débridement, decompression, bone graft, and reconstruction. (E) A postoperative sagittal CT scan obtained at the 12-month followup shows complete bone fusion. SVA = sagittal vertical axis; $\mathrm{TS}=\mathrm{T} 1$ slope; $\mathrm{TIA}=$ thoracic inlet angle; $\mathrm{NT}=$ neck tilt; $\mathrm{CG}=$ center of gravity.
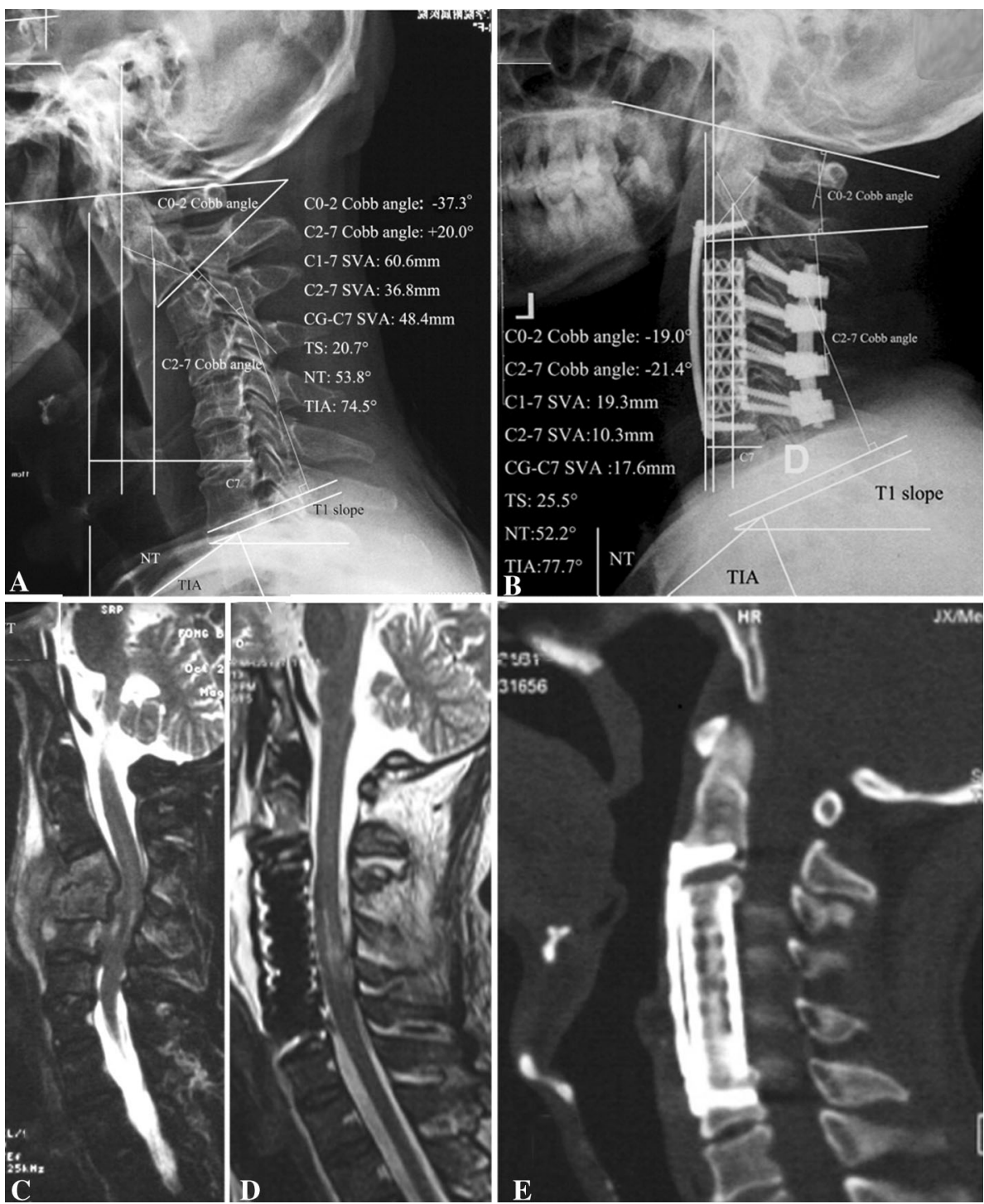

reported outcomes were identified by Pearson's test. Multiple stepwise regression was used to compare the related parameters.

\section{Results}

Surgical Results and Postoperative Cervical Sagittal Realignment

Most radiographic parameters showed clinically important improvements after surgery, and all patients had osseous fusion observed on CT scans, with bridging bone through the mesh or graft, although two patients lost correction after surgery because of titanium mesh subsidence. The mean duration of the operation was 100 minutes (range, 80-140 minutes), mean intraoperative blood loss was
$420 \mathrm{~mL}$ (range, 300-580 $\mathrm{mL}$ ), and mean hospital stay was 8 days (range, 5-12 days). All incisions healed primarily, there was no recurrence of cervical spinal tuberculosis, and no iatrogenic neurologic injuries occurred (Table 2). The preoperative $\mathrm{C} 0-2$ Cobb angle improved after surgery $\left(-28^{\circ} \pm 11^{\circ}\right.$ versus $-23^{\circ} \pm 4.2^{\circ}$; mean difference, 5.0 ; 95\% CI, 2.3 $\left.{ }^{\circ}-7.7^{\circ} ; \mathrm{p}=0.0068\right)$, as did C2-7 Cobb angle $\left(17^{\circ} \pm 5.2^{\circ}\right.$ versus $-16^{\circ} \pm 7.5^{\circ}$; mean difference, $-33^{\circ}$; $95 \% \mathrm{CI},-35^{\circ}$ to $\left.-31^{\circ} ; \mathrm{p}=0.0074\right), \mathrm{C} 2-7$ sagittal vertical axis $(38 \pm 6.7 \mathrm{~mm}$ versus $10 \pm 5.8 \mathrm{~mm}$; mean difference, $-28 \mathrm{~mm}$; $95 \% \mathrm{CI},-30$ to $-26 \mathrm{~mm}$; $\mathrm{p}=0.0036), \mathrm{CG}-7$ sagittal vertical axis $(47 \pm 8.3 \mathrm{~mm}$ versus $21 \pm 6.2 \mathrm{~mm}$; mean difference, $-26 \mathrm{~mm}$; $95 \% \mathrm{CI},-28$ to $-24 \mathrm{~mm}$; $\mathrm{p}=0.0049), \mathrm{T} 1$ slope $\left(16^{\circ} \pm 8.1^{\circ}\right.$ versus $22^{\circ} \pm 7.3^{\circ}$; mean difference, $\left.6.0^{\circ} ; 95 \% \mathrm{CI}, 3.7^{\circ}-8.3^{\circ} ; \mathrm{p}=0.0053\right)$, and the thoracic inlet angle $\left(63^{\circ} \pm 16^{\circ}\right.$ versus $71^{\circ} \pm 13^{\circ}$; mean difference, $\left.8.0^{\circ} ; 95 \% \mathrm{CI}, 3.7^{\circ}-12^{\circ} ; \mathrm{p}=0.0072\right)$. 
Table 2. Followup laboratory tests and clinical scoring

\begin{tabular}{lllll}
\hline Variables & CRP $(\mathrm{mg} / \mathrm{L})$ & ESR $(\mathrm{mm} / \mathrm{hour})$ & NDI score & JOA score \\
\hline Preoperative & $51 \pm 16$ & $69 \pm 25$ & $34 \pm 5.1$ & $32-35$ \\
95\% CI & $46-56$ & $62-77$ & $17 \pm 4.6$ & $6.6-7.8$ \\
Followup & $6.8 \pm 3.7$ & $14 \pm 5.4$ & $15-18$ & $13 \pm 2.6$ \\
$95 \%$ CI & $5.7-7.9$ & $12-15$ & $-17 \pm 4.9$ & $13-14$ \\
Mean difference & $-44 \pm 15$ & $-56 \pm 23$ & -18 to -16 & $6.1 \pm 2.3$ \\
$95 \%$ CI & -48 to -40 & -63 to -49 & 0.0096 & 0.0094 \\
p value & 0.0075 & 0.0043 & 6.8 \\
\hline
\end{tabular}

$\mathrm{CRP}=\mathrm{C}$-reactive protein; ESR = erythrocyte sedimentation rate; NDI = Neck Disability Index; JOA = Japanese Orthopaedic Association.

Table 3. Parameters of cervical sagittal alignment

\begin{tabular}{|c|c|c|c|c|c|c|c|}
\hline Variables & $\mathrm{C} 0-2 \mathrm{CA}$ & $\mathrm{C} 2-7 \mathrm{CA}$ & C2-7 SVA (mm) & CG-7 SVA (mm) & T1 slope & Thoracic inlet angle & Neck tilt \\
\hline Preoperative & $-28^{\circ} \pm 11^{\circ}$ & $17^{\circ} \pm 5.2^{\circ}$ & $38 \pm 6.7$ & $47 \pm 8.3$ & $16^{\circ} \pm 8.1^{\circ}$ & $63^{\circ} \pm 16^{\circ}$ & $49.2^{\circ} \pm 3.1^{\circ}$ \\
\hline $95 \% \mathrm{CI}$ & $-32^{\circ}$ to $-25^{\circ}$ & $15^{\circ}-18^{\circ}$ & $36-40$ & $44-49$ & $13^{\circ}-18^{\circ}$ & $58^{\circ}-67^{\circ}$ & $48^{\circ}-50^{\circ}$ \\
\hline Followup & $-23^{\circ} \pm 4.2^{\circ}$ & $-16^{\circ} \pm 7.5^{\circ}$ & $10 \pm 5.8$ & $21 \pm 6.2$ & $22^{\circ} \pm 7.3^{\circ}$ & $71^{\circ} \pm 13^{\circ}$ & $49.0^{\circ} \pm 2.0^{\circ}$ \\
\hline $95 \% \mathrm{CI}$ & $-24^{\circ}$ to $-22^{\circ}$ & $-18^{\circ}$ to $-14^{\circ}$ & $8.5-12$ & $19-22$ & $20^{\circ}-24^{\circ}$ & $67^{\circ}-74^{\circ}$ & $48^{\circ}-50^{\circ}$ \\
\hline Mean difference & $5.0^{\circ} \pm 9.3^{\circ}$ & $-33^{\circ} \pm 6.7^{\circ}$ & $-28 \pm 6.3$ & $-26 \pm 7.5$ & $6.0^{\circ} \pm 7.7^{\circ}$ & $8.0^{\circ} \pm 15^{\circ}$ & $-0.2^{\circ} \pm 2.7^{\circ}$ \\
\hline $95 \% \mathrm{CI}$ & $2.3^{\circ}-7.7^{\circ}$ & $-35^{\circ}$ to $-31^{\circ}$ & -30 to -26 & -28 to -24 & $3.7^{\circ}-8.3^{\circ}$ & $3.7^{\circ}-12^{\circ}$ & $-1.0^{\circ}$ to $0.6^{\circ}$ \\
\hline $\mathrm{p}$ Value & 0.0068 & 0.0074 & 0.0036 & 0.0049 & 0.0053 & 0.0072 & 0.079 \\
\hline
\end{tabular}

$\mathrm{CA}=\mathrm{Cobb}$ angle; $\mathrm{SVA}=$ sagittal vertical axis; $\mathrm{CG}=$ center of gravity.

With the numbers available, neck tilt angle did not improve $\left(49.2^{\circ} \pm 3.1^{\circ}\right.$ versus $49.0^{\circ} \pm 2.0^{\circ} ;$ mean difference, $-0.2^{\circ} ; 95 \% \mathrm{CI},-1.0^{\circ}$ to $0.6^{\circ} ; \mathrm{p}=0.079$ ) (Table 3 ).

\section{Patient-reported Outcomes Scores and Laboratory Findings}

We found that NDI and JOA score showed the patientreported outcomes had improved at followup (Table 2). The NDI decreased from $34 \pm 5.1$ before surgery to $17 \pm 4.6$ at latest followup (mean difference, $-17 ; 95 \%$ $\mathrm{CI},-18$ to $-16 ; \mathrm{p}=0.0096)$, as did JOA score $(7.2 \pm 1.9$ versus $13 \pm 2.6$; mean difference, 6.1; 95\% CI, 5.4-6.8; $\mathrm{p}=0.0094)$. Moreover, postoperative ESR and CRP had decreased to normal values in all patients.

\section{Correlations Between Postoperative Cervical \\ Realignment and Patient-reported Outcomes}

In most respects, the magnitude of the deformity correction correlated with improvements in the NDI. However, with the numbers available, this correlation was not observed between deformity correction and the JOA score. Specifically, we found postoperative NDI was correlated with the magnitude of correction of cervical deformity, including
C0-2 Cobb angle $(\mathrm{r}=-0.357, \mathrm{p}=0.007), \mathrm{C} 2-7$ Cobb angle $(\mathrm{r}=0.410, \mathrm{p}=0.002), \mathrm{T} 1$ slope $(\mathrm{r}=-0.366$, $\mathrm{p}=0.006)$, thoracic inlet angle $(\mathrm{r}=-0.376, \mathrm{p}=0.005)$, $\mathrm{C} 2-7$ sagittal vertical axis $(\mathrm{r}=0.450, \mathrm{p}=0.001)$, and CG-C7 sagittal vertical axis $(r=0.361, p=0.007)$. However, the JOA score did not correlate with postoperative cervical realignment (Table 4), and neck tilt did not show a relationship with NDI and JOA score $(\mathrm{r}=-0.019$, $\mathrm{p}=0.450 ; \mathrm{r}=-0.025, \mathrm{p}=0.434)$. There also was no correlation with the numbers available between postoperative JOA score and parameters of cervical alignment. After controlling for potential confounding variables like Cobb angles and T1 slope, we found C2-7 sagittal vertical axis was the most influential factor related to NDI improvement $(\mathrm{r}=0.450, \mathrm{p}=0.002$, multiple stepwise regression analysis) (Table 5).

\section{Discussion}

Cervical spinal tuberculosis often preferentially involves the anterior column and leaves the posterior column relatively uninvolved. This can result in cervical kyphosis, abnormal gaze, spinal cord compression, and subsequent neurologic deficits as the pathologic process enfolds the cervical ligaments or tethers the nerve roots [2, 16, 21, 24]. Antituberculosis chemotherapy is systemically effective, 
Table 4. Pearson correlation analysis results between cervical sagittal alignment parameters and patient-reported outcomes

\begin{tabular}{cccccccc}
\hline Variables & C0-2 Cobb angle & C2-7 Cobb angle & C2-7 SVA & CG-C7 SVA & T1 slope & Thoracic inlet angle & Neck tilt \\
\hline NDI & & & & & & & -0.019 \\
$\mathrm{r}$ & -0.357 & 0.41 & 0.45 & 0.361 & -0.366 & -0.376 & 0.45 \\
$\mathrm{p}$ & 0.007 & 0.002 & 0.001 & 0.007 & 0.006 & 0.005 & -0.025 \\
$\mathrm{JOA}$ & & & & & & 0.143 & 0.434 \\
$\mathrm{r}$ & 0.142 & -0.04 & -0.078 & -0.037 & 0.148 & 0.176 \\
$\mathrm{p}$ & 0.174 & 0.397 & 0.303 & 0.404 & 0.163 & 0.171 & \\
\hline
\end{tabular}

$\mathrm{SVA}=$ sagittal vertical axis; $\mathrm{CG}=$ center of gravity; NDI = neck disability index; JOA = Japanese Orthopaedic Association.

Table 5. Results of multiple stepwise regression analysis

\begin{tabular}{lcrll}
\hline Variables & Coefficient & $\mathrm{t}$ & $\mathrm{r}$ & $\mathrm{p}$ Value \\
\hline NDI & & & & \\
C2-7 SVA & 0.306 & 3.343 & 0.450 & 0.002 \\
Constant & 13.538 & 12.772 & & 0 \\
\hline
\end{tabular}

NDI $=$ Neck Disability Index; SVA = sagittal vertical axis.

but it does not address the kyphosis, whereas débridement and instrumentation appear to be effective in arresting the disease and providing support until solid spinal fusion is achieved $[1,5]$. Tuberculotic cervical kyphosis also causes pain and stiffness resulting from forward shifting of the head and neck, which induces abnormal loading forces. Therefore restoring malalignment of cervical spinal tuberculosis with kyphosis to normal cervical sagittal alignment may relieve the neck symptoms. To our knowledge, no studies have evaluated the association of correction of tuberculosis-related cervical deformities and patient-reported outcomes improvements in patients with kyphotic cervical spinal tuberculosis. We found cervical sagittal alignment, NDI, and JOA to be improved, and improved cervical alignment generally was correlated with improved NDI scores, but not with JOA scores.

There are some limitations to the study. First, four surgeons (KC, LY, JL, and ZL) participated in this study, but patients' spinal constructs used for these surgical procedures were not controlled nor completely standardized. Therefore we could not evaluate the influence of certain differences related to instrumentation or graft choices. In terms of surgical approaches, $85 \%$ (39/46) of the procedures were performed through only anterior surgeries, while $15 \%$ (seven of 46) were conducted through anterior and posterior combined approaches. Third, postoperative rehabilitation might have influenced the results in those patients, however, we believe the influence was small, since most patients did not undergo rehabilitation programs.

In this cohort, cervical kyphosis was effectively corrected to normal lordosis via anterior cervical reconstruction or combined AP reconstruction (the latter in patients with three or more levels of involvement). Kim et al. [7] showed that C2-7 lordosis, C2-7 sagittal vertical axis, and $\mathrm{T} 1$ slope were key parameters to assess cervical sagittal balance. In our series, C2-7 lordosis, C2-7 sagittal vertical axis, and $\mathrm{T} 1$ slope were restored to normal ranges as seen with our postoperative realignment data (Table 3). Currently, no studies of which we are aware have mentioned the changes of $\mathrm{C} 2-7$ sagittal vertical axis and $\mathrm{T} 1$ slope in the treatment of patients with kyphotic cervical spinal tuberculosis, but several have evaluated results with restoration of cervical lordosis. Zeng et al. [24] reported that in their series of cervical spinal tuberculosis, C2-7 lordosis improved from preoperative $41.4^{\circ} \pm 5.2^{\circ}$ to postoperative $-4.9^{\circ} \pm 4.9^{\circ}$. Liu et al. [14] reported improvement in cervical lordosis from preoperative $42.58^{\circ}$ (range, $30^{\circ}-67^{\circ}$ ) to postoperative $-8^{\circ}$ (range, $-15^{\circ}$ to $11^{\circ}$ ). Mao et al. [15] described a postoperative cervical lordosis of $-1.8^{\circ}$, which was improved from preoperative of $29^{\circ}$. Therefore, correcting the cervical kyphosis in patients with cervical spinal tuberculosis close to a normal cervical alignment is worthwhile.

In our study, most of the patients had severe neuropathic symptoms and functional disabilities with preoperative low JOA scores and high NDI scores (reflecting more severe disability). With surgery, improved JOA and NDI scores reflected improvements in postoperative neurologic results and neck function. Other than for neurologic functional improvement, no study of which we are aware has described neck function-related NDI score improvement after surgery for kyphotic cervical spinal tuberculosis. Liu et al. [14] investigated 12 patients with tuberculotic kyphosis of the cervical spine or cervicothoracic spine through a mean of 25 months followup and reported that postoperative JOA scores improved after surgery. Zeng et al. [24] reported a clinical series of 12 children with cervical spinal tuberculosis kyphosis who underwent débridement, decompression, and $360^{\circ}$ cervical spinal arthrodesis, and found that neurologic function improved as well. In the study by Mao et al. [15], 21 patients with kyphotic cervical spinal tuberculosis received one-stage anterior 
débridement, autologous iliac bone grafting, and internal plate fixation. Of the 13 patients with symptoms of spinal cord compression, nine improved by one grade and four improved by two grades according to the Frankel classification at final followup.

We found that improvements in the NDI correlated well with improvements of spinal alignment after surgery, specifically as cervical lordosis was restored. Moreover, the NDI was correlated with postoperative $\mathrm{C} 0-2 \mathrm{Cobb}$ angle, C2-7 Cobb angle, T1 slope, thoracic inlet angle, C2-7 sagittal vertical axis, and CG-C7 sagittal vertical axis. We also found that $\mathrm{C} 2-7$ sagittal vertical axis was the mosttightly correlated parameter, which reflected forward shifting of the head and neck. The $\mathrm{C} 2-7$ sagittal vertical axis is the distance between a plumb line dropped from the centroid of $\mathrm{C} 2$ and another vertical line dropped from the posterosuperior corner of $\mathrm{C} 7$. In the normal cervical spine, it is distributed in a narrow range $(16.8 \pm 11.2 \mathrm{~mm})$ as measured in a study of asymptomatic volunteers [4]. Compared with other cervical sagittal parameters in patients with fusion at C5-6, Park et al. [17] found that postoperative $\mathrm{C} 2-7$ sagittal vertical axis is more related to clinical adjacent segment disorders, which could be treated by surgery after anterior cervical arthrodesis. Tang et al. [21] suggested that increasing C2-7 sagittal vertical axis is associated with poor patient-reported outcomes (negatively correlated with SF-36 physical component scores) in patients undergoing cervical fusion for cervical stenosis, myelopathy, and kyphosis; moreover, a C2-7 sagittal vertical axis greater than $4 \mathrm{~cm}$ was correlated with worse outcomes assessed by the NDI. Hu et al. [6] reported that patients with restored $\mathrm{C} 2-7$ lordosis and $\mathrm{C} 2-7$ sagittal vertical axis had greater NDI improvements after surgery. In the current study, we found improved cervical lordosis helped to rebalance the head over the thoracic inlet, which is composed of the T1 vertebral body, the first ribs on both sides, and the upper part of the sternum. Generally, a greater magnitude of cervical lordosis results in larger $\mathrm{T} 1$ slope and thoracic inlet angle, just as a larger lumbar lordosis leads to greater sacral slope. Moreover, T1 slope also correlated with a positive sagittal balance of C2-7 sagittal vertical axis and $\mathrm{C} 2-7$ lordosis in asymptomatic volunteers $[8,15]$. Our data also indicated that NDI improvement correlated with $\mathrm{T} 1$ slope and thoracic inlet angle after surgery. However, through regression analysis, we found that the C2-7 sagittal vertical axis was the key factor associated with NDI. The JOA score mainly reflects cervical spinal cord function, but not neck pain and stiffness, which are closely reflected by the NDI score. This may explain why cervical sagittal alignment and JOA score were not clearly related in this cohort, an idea supported by Lee et al. [9]. They suggested that cervical sagittal alignment after laminoplasty was not associated with clinical outcomes in terms of postoperative improvement of the JOA score.

Débridement and cervical reconstruction can realign the spine in patients with kyphotic cervical spinal tuberculosis, and improve NDI and JOA scores. NDI improvement is correlated with $\mathrm{C} 0-2 \mathrm{Cobb}$ angle, $\mathrm{C} 2-7 \mathrm{Cobb}$ angle, $\mathrm{C} 2-7$ sagittal vertical axis, CG-C7 sagittal vertical axis, T1 slope, and thoracic inlet angle. $\mathrm{C} 2-7$ sagittal vertical axis was the parameter most-closely associated with improvements in the NDI. Therefore, we recommend that when treating patients with kyphotic cervical spinal tuberculosis by débridement, decompression, and reconstruction, more attention should be paid to realigning the cervical spine, in particular to restore the $\mathrm{C} 2-7$ sagittal vertical axis. However, how best to restore the $\mathrm{C} 2-7$ sagittal vertical axis and cervical alignment in a kyphotic cervical spine needs further study.

Acknowledgments We thank the reviewers and editors for their helpful comments on this article.

\section{References}

1. Alam MS, Phan K, Karim R, Jonayed SA, Munir HK, Chakraborty S, Alam T. Surgery for spinal tuberculosis: a multi-center experience of 582 cases. J Spine Surg. 2015;1:65-71.

2. Bu G, Shuang F, Liu G, Wu Y, Hou S, Ren D, Shang W. Efficacy and safety of one-stage selective discectomy combined with expansive hemilaminectomy in the treatment of cervical spondylotic myelopathy. World Neurosurg. 2016;94:507-512.

3. Cho CH, Song KS, Hwang I, Warner JJ. Does rotator cuff repair improve psychologic status and quality of life in patients with rotator cuff tear? Clin Orthop Relat Res. 2015;473:3494-3500.

4. Hardacker JW, Shuford RF, Capicotto PN, Pryor PW. Radiographic standing cervical segmental alignment in adult volunteers without neck symptoms. Spine (Phila Pa 1976). 1997;22:14721480; discussion 1480.

5. Hou K, Yang H, Zhang L, Zhang X, Xiao S, Lu N. Stepwise therapy for treating tuberculosis of the upper cervical spine: a retrospective study of 11 patients. Eur Neurol. 2015;74:100-106.

6. Hu X, Ohnmeiss DD, Zigler JE, Guyer RD, Lieberman IH. Restoration of cervical alignment is associated with improved clinical outcome after one and two level anterior cervical discectomy and fusion. Int J Spine Surg. 2015;9:61.

7. Kim KN, Ahn PG, Ryu MJ, Shin DA, Yi S, Yoon DH, Ha Y. Long-term surgical outcomes of cervical myelopathy with athetoid cerebral palsy. Eur Spine J. 2014;23:1464-1471.

8. Knott PT, Mardjetko SM, Techy F. The use of the T1 sagittal angle in predicting overall sagittal balance of the spine. Spine $J$. 2010;10:994-998.

9. Lee CK, Shin DA, Yi S, Kim KN, Shin HC, Yoon DH, Ha Y. Correlation between cervical spine sagittal alignment and clinical outcome after cervical laminoplasty for ossification of the posterior longitudinal ligament. J Neurosurg Spine. 2016;24:100107.

10. Lee JS, Youn MS, Shin JK, Goh TS, Kang SS. Relationship between cervical sagittal alignment and quality of life in ankylosing spondylitis. Eur Spine J. 2015;24:1199-1203.

11. Lee SH, Kim KT, Seo EM, Suk KS, Kwack YH, Son ES. The influence of thoracic inlet alignment on the craniocervical sagittal 
balance in asymptomatic adults. $J$ Spinal Disord Tech. 2012;25:E41-47.

12. Lee SH, Lee JC, Tauchi R, Daniel Riew K. Influence of the number of cervical fusion levels on cervical spine motion and health-related quality of life. Spine (Phila Pa 1976). 2016;41:E474-480.

13. Ling T, Liu L, Yang X, Qiang Z, Hu X, An Y. Revision surgery for spinal tuberculosis with secondary deformity after treatment with debridement, instrumentation, and fusion. Eur Spine J. 2015;24:577-585.

14. Liu Y, Chen Y, Yang L, Zhou X, Wang C, Qi M, Yuan W. The surgical treatment and related management for post-tubercular kyphotic deformity of the cervical spine or the cervico-thoracic spine. Int Orthop. 2012;36:367-372.

15. Mao N, Shi Z, Ni H, Zhao Y, Tang H, Liu D, Zhu X, Bai Y, Li M. Long-term outcomes of one-stage anterior debridement, bone grafting, and internal fixation for the treatment of lower cervical tuberculosis with kyphosis. Br J Neurosurg. 2013;27:160-166.

16. Ozdemir HM, Us AK, Ogun T. The role of anterior spinal instrumentation and allograft fibula for the treatment of Pott disease. Spine (Phila Pa 1976). 2003;28:474-479.

17. Park MS, Kelly MP, Lee DH, Min WK, Rahman RK, Riew KD. Sagittal alignment as a predictor of clinical adjacent segment pathology requiring surgery after anterior cervical arthrodesis. Spine J. 2014;14:1228-1234.

18. Qu JT, Jiang YQ, Xu GH, Tang Y, Wang ZT, Ye XJ, Shi GH, Dong JW, Li J, Zhou JL, Hu Y. Clinical characteristics and neurologic recovery of patients with cervical spinal tuberculosis: should conservative treatment be preferred? A retrospective followup study of 115 cases. World Neurosurg. 2015;83:700-707.

19. Scheer JK, Tang JA, Smith JS, Acosta FL Jr, Protopsaltis TS, Blondel B, Bess S, Shaffrey CI, Deviren V, Lafage V, Schwab F, Ames CP; International Spine Study Group. Cervical spine alignment, sagittal deformity, and clinical implications: a review. J Neurosurg Spine. 2013;19:141-159.

20. Shi T, Zhang Z, Dai F, Zhou Q, He Q, Luo F, Hou T, Xu J. Retrospective study of 967 patients with spinal tuberculosis. Orthopedics. 2016;39:e838-843.

21. Tang JA, Scheer JK, Smith JS, Deviren V, Bess S, Hart RA, Lafage V, Shaffrey CI, Schwab F, Ames CP; ISSG. The impact of standing regional cervical sagittal alignment on outcomes in posterior cervical fusion surgery. Neurosurgery. 2012;71:662669; discussion 669.

22. Vernon H, Mior S. The Neck Disability Index: a study of reliability and validity. J Manipulative Physiol Ther. 1991;14:409415.

23. Wang L, Liu L, Song Y, Pei F, Liu H. Cervical tuberculosis associated with cervical pain and neurologic deficit: a case report and literature review. Spine J. 2014;14:e13-18.

24. Zeng H, Shen X, Luo C, Xu Z, Zhang Y, Liu Z, Wang X, Cao Y. 360-degree cervical spinal arthrodesis for treatment of pediatric cervical spinal tuberculosis with kyphosis. BMC Musculoskelet Disord. 2016;17:175.

25. Zumla A, George A, Sharma V, Herbert N, Baroness Masham of Ilton. WHO's 2013 global report on tuberculosis: successes, threats, and opportunities. Lancet. 2013;382:1765-1767. 